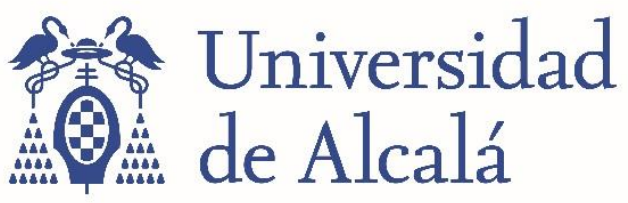

BIBLIOTECA

Document downloaded from the institutional repository of the University of Alcala: http://dspace.uah.es/dspace/

This is a postprint version of the following published document:

Heidi Lees, Félix Zapata, Merike Vaher, Carmen García-Ruiz 2018, "Simple multispectral imaging approach for determining the transfer of explosive residues in consecutive fingerprints", Talanta, 184, pp. 437-445.

Available at: DOI: 10.1016/j.talanta.2018.02.079

(C) 2018 Elsevier
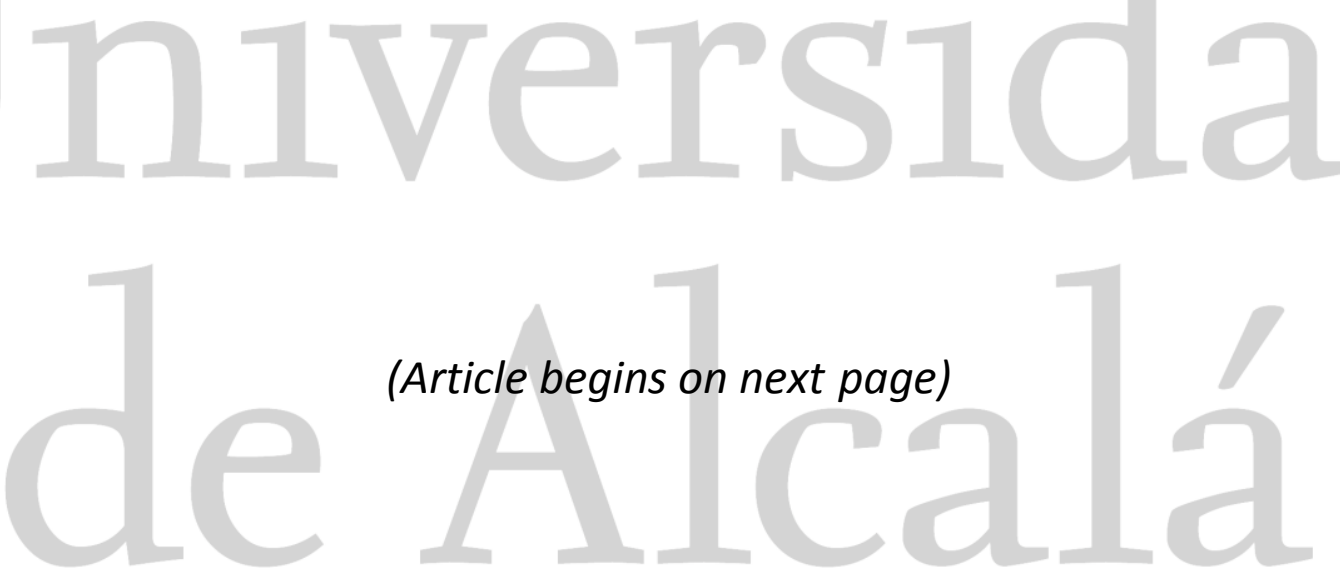

(Article begins on next page)

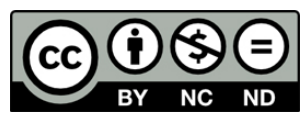

This work is licensed under a

Creative Commons Attribution-NonCommercial-NoDerivatives

4.0 International License. 


\title{
Simple multispectral imaging approach for determining the transfer of explosive residues in consecutive fingerprints
}

\author{
Heidi Lees ${ }^{\mathrm{a}}$, Félix Zapata ${ }^{\mathrm{b}}$, Merike Vaher ${ }^{\mathrm{a}}$, Carmen García-Ruiz ${ }^{\mathrm{b}}$
}

a Department of Chemistry, Institute of Chemistry and Biotechnology, Tallinn University of Technology, Akadeemia tee 15, 12618 Tallinn, Estonia

b Inquifor Research Group, Department of Analytical Chemistry, Physical Chemistry and Chemical Engineering and University Institute of Research in Police Sciences (IUICP), University of Alcalá, 28871 Alcalá de Henares, Spain

Emails: carmen.gruiz@uah.es; felix.zapata@uah.es

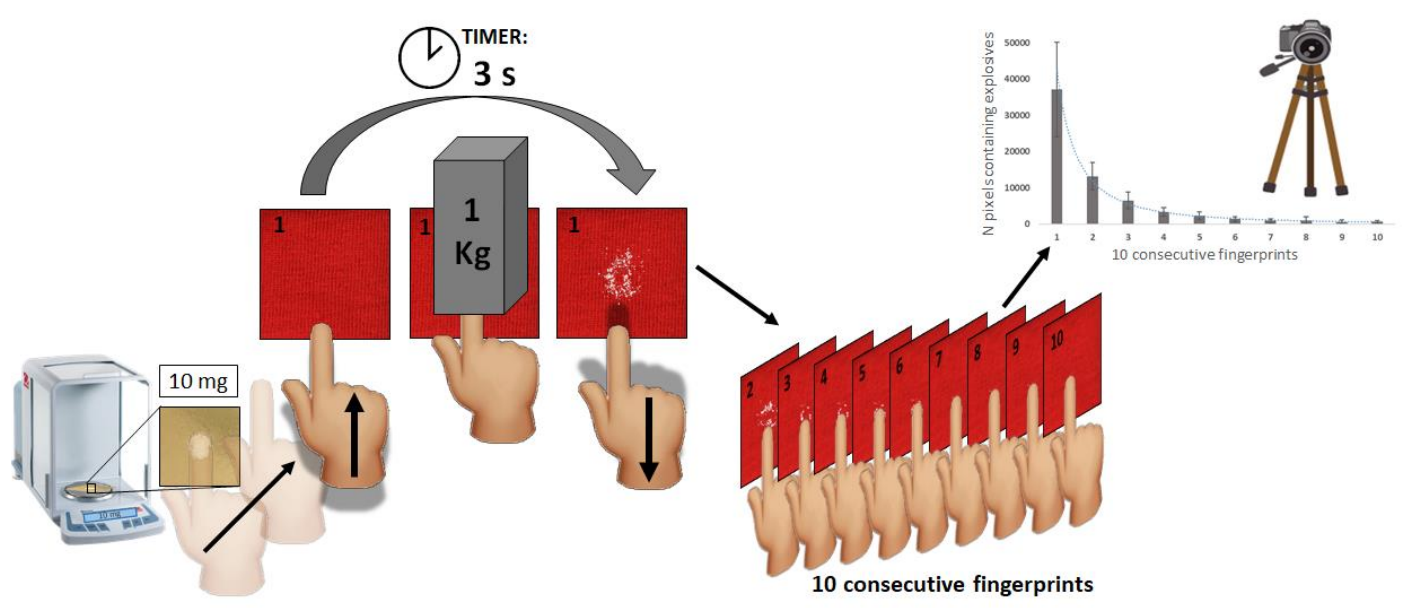

Cite: H. Lees, F. Zapata, M. Vaher, C. García-Ruiz, Simple multispectral imaging approach for determining the transfer of explosive residues in consecutive fingerprints, Talanta 184 (2018) 437-445. DOI: $\underline{\text { 10.1016/j.talanta.2018.02.079 }}$ 


\begin{abstract}
This novel investigation focused on studying the transfer of explosive residues (TNT, HMTD, PETN, ANFO, dynamite, black powder, $\mathrm{NH}_{4} \mathrm{NO}_{3}, \mathrm{KNO}_{3}, \mathrm{NaClO}_{3}$ ) in ten consecutive fingerprints to two different surfaces - cotton fabric and polycarbonate plastic - by using multispectral imaging (MSI). Imaging was performed employing a reflex camera in a purpose-built photo studio. Images were processed in MATLAB to select the most discriminating frame - the one that provided the sharpest contrast between the explosive and the material in the red-green-blue (RGB) visible region. The amount of explosive residues transferred in each fingerprint was determined as the number of pixels containing explosive particles. First, the pattern of PETN transfer by ten different persons in successive fingerprints was studied. No significant differences in the pattern of transfer of PETN between subjects were observed, which was also confirmed by multivariate analysis of variance (MANOVA). Then, the transfer of traces of the nine above explosives in ten consecutive fingerprints to cotton fabric and polycarbonate plastic was investigated. The obtained results demonstrated that the amount of explosive residues deposited on successive fingerprints tended to undergo a power or exponential decrease, with the exception of inorganic salts $\left(\mathrm{NH}_{4} \mathrm{NO}_{3}, \mathrm{KNO}_{3}, \mathrm{NaClO}_{3}\right)$ and $\mathrm{ANFO}$ (consists of $\left.90 \% \mathrm{NH}_{4} \mathrm{NO}_{3}\right)$.
\end{abstract}

Keywords: Explosive residues, Transfer, Fingerprint, Multispectral imaging. 


\section{Introduction}

In recent years, numerous terrorist attacks have taken place globally, representing a constant threat to citizens in many countries. It is very probable that when a terrorist handles an explosive, there will remain a certain amount of explosive residues on his/her hands and clothes. Therefore, the detection of explosive traces directly from the hands and cloths of suspects [1-3] or through the collection of the explosive traces by swabbing [4-8] has been the subject of many studies. In this regard, Perret et al. [4] demonstrated that handling of different explosives resulted in significant transfer of explosives to the hands and traces were still detectable even after washing hands with soap. Furthermore, explosive residues may be transferred from contaminated hands and clothes to other items, such as laptops, luggage, etc. The search for and detection of trace amounts of explosives on people and objects at airports and other high-risk venues is a major challenge in counterterrorism activities $[9,10]$. The transfer of explosive residues through a person's fingerprints enables the detection of concealed explosives through surface sampling [11]. As a matter of fact, fingerprints are one of the main means for transferring trace amounts of explosives during handling and preparation of improvised explosive devices [12]. To date, significant progress has been made in the detection of explosive traces in fingerprints [12-21]. Lately, there has been keen interest in developing methods for the rapid detection of explosive residues in fingerprints by using various spectroscopic, imaging and microscopic techniques, including laser-induced breakdown spectroscopy [12,22,23], X-ray fluorescence [24], vibrational spectroscopy (infrared [1,2,17,25-27] and Raman [14,28-32]) and visible spectroscopy [33]. Most studies are focused on detecting and identifying the explosive residues from fingerprints placed on different surfaces, which is the most important goal for counterterrorism purposes.

However, the transfer of explosives in consecutive fingerprints to those materials on which they are detected has been scarcely studied. In this respect, Turano [34] quantified the amount of $\mathrm{NH} 4 \mathrm{NO} 3$ and $\mathrm{KClO} 3$ deposited by successive fingerprints on three different surfaces (filter paper, polypropylene, and polyurethane) by using ion chromatography. Verkouteren et al. [10] analyzed and characterized fifty composition-4 (C-4) fingerprints by using polarized light microscopy and image analysis. Gresham et al. [35] determined the mass of 1,3,5-trinitroperhydro-1,3,5-triazine (RDX) and the particle size distribution of the C-4 residues deposited on polyethylene films by fingerprint transfer. Mass of RDX was determined by gas chromatography and the 
particle size distribution of residues was determined by microscopic examination. Choi and Son [36] used ion mobility spectrometry to detect traces of RDX and TNT transferred to three smear matrices - stainless steel mesh, cellulose paper and cotton fabric - by using a stainless steel roller.

Spectral imaging is a well-known non-destructive, fast and inexpensive technique with high potential for studying the transfer of explosive residues since it combines the spectral and spatial information about the imaged sample [17]. Although, selective spectral ranges using infrared or Raman vibrational spectroscopy are needed for explosives identification, the identification of explosives was not the objective of this study. This work aims to study the transfer of known explosives through successive fingerprints to different materials. For this purpose, the simplest visible multispectral imaging (MSI) system consisting of red-green-blue (RGB) wavelengths that operate in professional and non-professional cameras as well as mobile phones was applied. The goal of the study was to develop a simple approach for acquiring fundamental knowledge about the transfer of explosive residues in ten consecutive fingerprints to two different surfaces, cotton fabric and polycarbonate plastic.

\section{Materials and methods}

\subsection{Explosives and inorganic salts}

In this research, the transfer of nine different explosive residues -TNT, HMTD, PETN, dynamite, ANFO, black powder, $\mathrm{NH}_{4} \mathrm{NO}_{3}, \mathrm{KNO}_{3}, \mathrm{NaClO}_{3}$ - was examined. Organic explosives and explosive mixtures were obtained from TEDAX, Spanish Explosive Ordnance Disposal (EOD). Inorganic salts $\left(\mathrm{NH}_{4} \mathrm{NO}_{3}, \mathrm{KNO}_{3}, \mathrm{NaClO}_{3}\right)$ were purchased from Sigma-Aldrich (St. Louis, MO, USA) and were of ACS reagent grade (purity>98\%). The composition and average particle diameter of the studied explosive residues are given in Table 1. However, during the experiments it was observed that, in some cases, the particles of explosives became aggregated because of the pressing/transfer procedure.

\subsection{Sample preparation and fingerprint collection}


HMTD, PETN, ANFO, black powder, $\mathrm{NH}_{4} \mathrm{NO}_{3}, \mathrm{KNO}_{3}$ and $\mathrm{NaClO}_{3}$ were obtained already in powdered form and were used without any pretreatment before experiments. Initial experiments showed that big and heavy particles of non-treated TNT $(\approx 5 \mathrm{~mm}$ particles and $12-13 \mathrm{mg}$ ) and dynamite ( $2 \mathrm{~cm}$ cylindrical cartridge) did not adhere to the finger and therefore transfer did not occur. Due to this, it was decided to prepare powdered dynamite and TNT in order to study the transfer of explosives with a similar weight $(10 \mathrm{mg})$ and range of particle sizes $(<1 \mathrm{~mm})$. For this, TNT was dissolved in acetonitrile. The solution was left to dry overnight to enable evaporation of acetonitrile. As a result, the powdered TNT remained on Petri dish. Dynamite was mechanically powdered in the mortar. The particle sizes after these pretreatments are indicated in Table 1.

Table 1. Composition and average particle diameter of the studied explosive residues.

\begin{tabular}{|l|l|l|}
\hline $\begin{array}{c}\text { Explosive } \\
\text { residues }\end{array}$ & \multicolumn{1}{|c|}{ Composition ${ }^{\mathrm{a}}$} & \multicolumn{1}{|c|}{$\begin{array}{c}\text { Average particle } \\
\text { diameter }(\mu \mathrm{m})\end{array}$} \\
\hline $\mathrm{NH}_{4} \mathrm{NO}_{3}$ & Ammonium nitrate $(100 \%)$ & $\approx 300$ \\
\hline $\mathrm{KNO}_{3}$ & Potassium nitrate $(100 \%)$ & $\approx 400$ \\
\hline $\mathrm{NaClO}_{3}$ & Sodium chlorate $(100 \%)$ & $\approx 500$ \\
\hline ANFO & Ammonium nitrate $(90 \%)+$ diesel $(10 \%)$ & $\approx 500$ \\
\hline Dynamite* & $\begin{array}{l}\text { Ammonium nitrate }(66 \%)+\text { ethylene glycol dinitrate }(29 \%)+ \\
\text { nitrocellulose }(1 \%)+\text { dibutyl phthalate }(2.5 \%)+\text { sawdust }(1.2 \%)+\end{array}$ & $\approx 300$ \\
& calcium carbonate $(0.3 \%)$ & $\approx 400\left(\mathrm{KNO}_{3}\right)$ \\
\hline Black powder & Potassium nitrate $(75 \%)+$ charcoal $(15 \%)+$ sulfur $(10 \%)$ & $\approx 50($ charcoal $)$ \\
\hline TNT* & $2,4,6-$ Trinitrotoluene $(100 \%)$ & $\approx 75$ \\
\hline HMTD & Hexamethylene triperoxide diamine $(100 \%)$ & $\approx 20$ \\
\hline PETN & Pentaerythritol tetranitrate $(100 \%)$ & $\approx 40$ \\
\hline
\end{tabular}

${ }^{a}$ Information provided by the manufacturer or by TEDAX (Spanish EOD).

${ }^{\mathrm{b}}$ Experimentally determined by averaging the diameter of 30-50 particles by using a Raman microscope (Thermo Scientific, Waltham, MA, USA).

* Particle diameter after sample preparation (Section 2.2).

Cotton fabric and polycarbonate plastic as the two most common clothing and luggage materials, respectively, were chosen to study the transfer of explosive residues through fingerprints. For experiments, a cotton T-shirt bought from a local supermarket was cut into $3 \times 3 \mathrm{~cm}$ pieces. A 5 -gallon (ca $19 \mathrm{~L}$ ) polycarbonate plastic water bottle was also cut into $3 \times 3 \mathrm{~cm}$ pieces, instead of using a real polycarbonate luggage.

The amount of explosive residues remaining in fingerprints depends on the initial amount present on a person's hands, the number of successive impressions made after contamination and the force applied by the contaminated finger [10,11]. Therefore, to take repeatable fingerprints, the applied force $(1 \mathrm{~kg})$ and time $(3 \mathrm{~s})$, were fixed to 
standardize the transfer procedure. The controlled force was applied by placing a $1-\mathrm{kg}$ cuboid bottle on the index finger while taking the fingerprints. The time was fixed with a stopper. Additionally, the printing surfaces were all prepared in the same manner and the fingerprints were taken by ensuring the contact of the whole index finger area with the surface. To ensure the presence of the same amount of natural oils and sweat in the finger, a subject's hands were always washed $15 \mathrm{~min}$ before each experiment. During these 15 min the normal routine work was allowed to continue. The initial amount of explosive was always balanced at around $10.00 \mathrm{mg}$ on a weighing pan using an Ohaus DV215CD analytical balance with a precision of 5 decimal places $(0.00001 \mathrm{~g})$. As previously evidenced in Table 1, the average particle size was different for each explosive, and consequently the number of particles contained in $10 \mathrm{mg}$ of substance was different for each explosive. For instance, $10 \mathrm{mg}$ meant 5-40 particles for inorganic salts $\left(\mathrm{KNO}_{3}\right.$, $\mathrm{NH}_{4} \mathrm{NO}_{3}$ and $\mathrm{NaClO}_{3}$ ), while hundreds/thousands of particles for organic explosives (PETN, HMTD, powdered TNT) and black powder (due to fine particles of charcoal). The number of particles for $10 \mathrm{mg}$ of ANFO and dynamite was intermediate.

\subsection{Instrumentation}

Fingerprints of explosive residues on the two studied surfaces were photographed using the Nikon D5000 Digital SLR Camera equipped with a 12.9 megapixel DX-format CMOS sensor and AF-S DX Zoom-Nikkor 18-55mm f/3.5-5.6G ED II lens. A purposebuilt photo studio having controlled light, tripod (a fixed height and perpendicular angle) and remote control was used to minimize the error of imaging. Pictures of samples were taken together with that of a clean blank sample (cotton or polycarbonate) to check the correct intensity value for the background of each picture. Three replicates per explosive and material were prepared. Using the remote control three consecutive photographs of each replicate were taken.

\subsection{Image processing}

Image processing was performed in MATLAB R2017a (MathWorks, USA) using a selfwritten code. The used image processing was similar to the previous study performed by this research group [37]. Three pictures of each replicate were processed as follows. The region of interest (ROI) was selected by removing the unnecessary edges of the image. 
Raw images contained $2848 \times 4288$ pixels $\times 3$ wavelengths, the spatial resolution of each pixel was $19.2 \times 19.2 \mu \mathrm{m}$. ROI involved a square selection of $1000 \times 1000$ pixels in the correct frame. In order to select the correct frame, the three RGB frames of each image were compared. The frame that provided the sharpest contrast between the explosive and the background material was chosen. This contrast was evaluated by both the visual inspection of the image and the numerical examination of the values in the matrix. For instance, in case of red cotton fabric and white explosive, the green frame was selected, while for polycarbonate plastic and white explosive, the red frame was selected, as summarized in Table 2. In fact, the selection of materials of the above colours was not random. Bearing in mind the aim of maximizing the contrast, materials of different colours (i.e. green, blue, red, grey, white and black cotton fabrics or paper sheets placed behind the transparent polycarbonate plastic) were initially examined. Of the tested materials, red cotton fabric provided the highest contrast for both white and dark explosives. Regarding the coloured paper sheet placed behind polycarbonate, black paper for white explosives, and light grey paper for black powder were selected.

Table 2. Selected frames and optimized intensity threshold values for counting the explosive particles on each surface.

\begin{tabular}{|c|c|c|}
\hline White explosives on red cotton & $\begin{array}{c}\text { RGB frame } \\
\text { selected }\end{array}$ & $\begin{array}{c}\text { Intensity threshold value }(0-1) \\
0=\text { completely black, 1= completely white }\end{array}$ \\
\hline Black powder on red cotton & $\begin{array}{c}\text { Red } \\
\text { Green }\end{array}$ & $>0.39$ \\
\hline $\begin{array}{c}\text { White explosives on polycarbonate } \\
\text { (dark background behind polycarbonate) }\end{array}$ & Red & $>0.34$ (white-grayish $\mathrm{KNO}_{3}$ particles)* \\
\hline $\begin{array}{c}\text { Black powder on polycarbonate } \\
\text { (light background behind polycarbonate) }\end{array}$ & Blue & $<0.59$ (black charcoal + white-grayish $\mathrm{KNO}_{3}$ \\
particles)*
\end{tabular}

* $\mathrm{KNO}_{3}$ particles were covered with charcoal and were therefore not completely white.

After selecting the proper frame, the amount of pixels containing explosive residues was quantified. To this end, pixels whose values of intensity in the specific frame exceeded a specific value were summed up. Different intensity thresholds were tested by controlling the maximum intensity present in the blank sample and assuring visually that the program would not count any pixels from the background. Then, the quantification of pixels in each image was performed through automatically counting the pixels whose intensity values were higher (in case of white explosives) or lower (in case of black powder) than 
the threshold value. For black powder on cotton fabric, the combination of two frames was employed and the number of greyish and black pixels were finally summed up. Table 2 summarizes the threshold values optimized for each surface and explosive to count the explosive particles on that surface.

After counting the pixels, the image was binarized, i.e. converted only to black and white (values 0 and 1 only) for better visualization. A simplified scheme of image processing in MATLAB for ANFO on cotton fabric is displayed in Fig. 1.

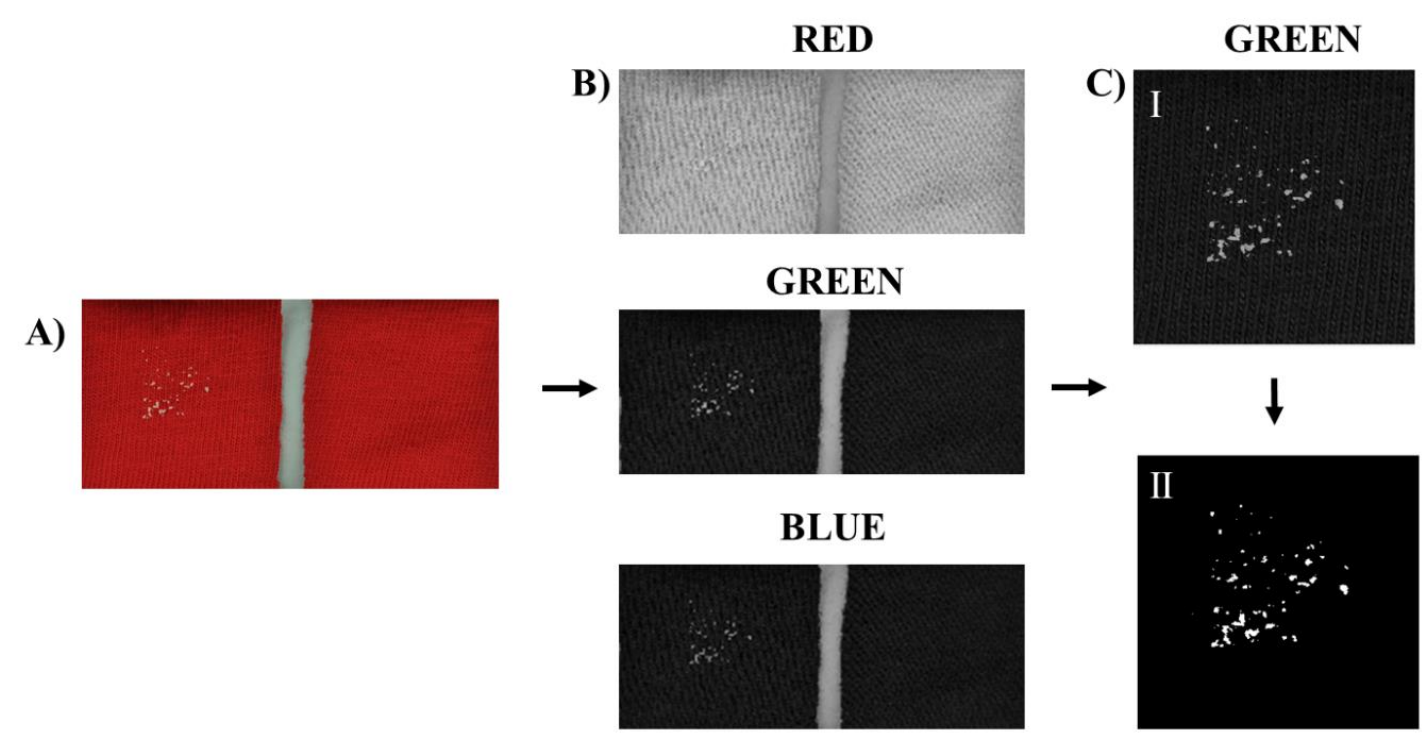

Fig. 1. Simplified scheme of image processing in MATLAB: A) explosive residues (ANFO) on cotton fabric (left) compared to a blank sample (right), B) RGB frames for evaluation and selection, C) selection of ROI in the correct frame (I) and binarization of the image (II).

It is important to point out that the number of pixels containing explosive residues in the image does not exactly respond to the number of explosive particles itself. The two reasons for this are that (a) the size of the particles is different even within the same explosive and (b) the particles may become aggregated during the pressing/transferring procedure, but only pixels in the upper layer of fingerprints are counted. Nevertheless, despite the above-mentioned shortcomings, some fundamental insights can be established about the transfer of explosive residues.

\subsection{Data treatment}


The numbers of pixels obtained by MATLAB were imported as a matrix to Excel (Microsoft Office 2016) and STATGRAPHICS Centurion XVI.I (Statpoint Technologies, Inc., USA). Different fitting trendlines using Excel were tested by evaluating the R2 coefficient. Multivariate Analysis of Variance (MANOVA) was performed in STATGRAPHICS to analyse the variance in the amount of pixels containing explosives among samples and replicates. Before performing MANOVA it was verified that data distribution was normal and linear, there was homogeneity of variances and no outliers were present. The number of dependent variables was 10 (ten fingerprints) to 1 predictive factor (subjects). In brief, an analysis of variance (ANOVA) was conducted for each variable separately, evaluating its performance at an alpha level of 0.05 . The multiple comparison procedure to discriminate among the means of transferred explosive residues between subjects was based on Fisher's least significant difference (LSD).

\section{Results and discussion}

\subsection{Transfer of explosive residues in ten consecutive fingerprints by ten}

\section{persons}

The transfer of PETN in ten consecutive fingerprints to cotton fabric was investigated. Ten consecutive fingerprints were taken of ten persons in triplicate. The test group consisted of five females and five males at the age between 22 and 29 years. A standardized procedure (as described in Section 2.2) for taking fingerprints was followed by all participants. To this end, the index finger of each person's right hand was exposed for $3 \mathrm{~s}$ to $10 \mathrm{mg}$ of the explosive powder on a weighing pan. After that, the fingertip with the explosive particles adhered to was pressed consecutively on ten pieces of cotton fabric. The amount of explosive particles remaining on the weighing pan was re-weighed after pressing the finger on the pan to determine the initial amount of explosive adhered to the subject's fingertip. This was done by subtracting the two weight values of the weighing pan (initial and after).

The amount of PETN adhered to the bare finger after pressing varied from 3.7 to $7.5 \mathrm{mg}$ between the subjects. Interestingly, the pattern of transfer of PETN through successive 
impressions to cotton fabric was similar in all subjects - the amount of explosive residues in the fingerprints decreased with the increasing number of fingerprintings.

The graph showing the average number of pixels containing PETN residues (with standard deviation) in each fingerprint taken of the ten subjects is depicted in Fig. 2. As an example, the pictures of ten consecutive fingerprints of PETN on cotton fabric taken of one person are also given in the figure.

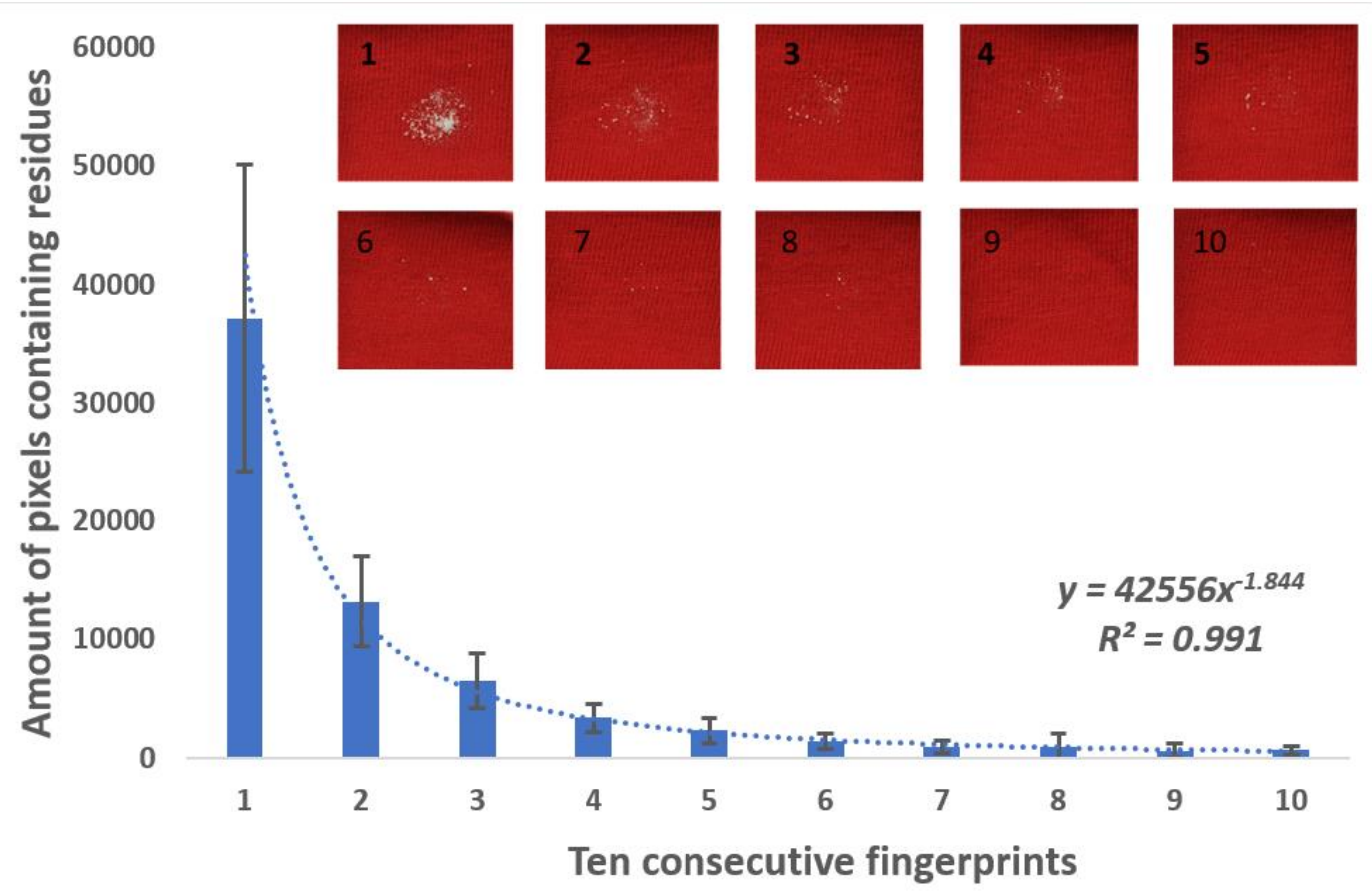

Fig. 2. Graph showing the variation of the amount of PETN (amount of pixels) transferred through ten successive fingerprints of ten persons. As an example, images of ten consecutive fingerprints of one person are shown (red squares 1-10).

According to the standard deviation bars seen on Fig. 2, it is evident that there were differences in the amounts of PETN (amount of pixels) transferred by the subjects despite employing the standardized fingerprinting procedure. However, even with those differences, the general results were the same - a similar decrease in the transferred amounts of PETN through successive fingerprints was observed for every person. In fact, this decrease of the transferred PETN amount in consecutive fingerprints may be explained using the power function $y=42556 x-1.844$ with an acceptable coefficient of determination $\left(\mathrm{R}^{2}=0.99\right)$.

In order to check whether the slight differences visually observed among the subjects were statistically significant, MANOVA was performed. Since the p-value for the first 
variable (the first fingerprint) was less than 0.05 (p-value was 0.0132), there was a statistically significant difference between the subjects considering the first fingerprint at a 95.0\% confidence level (i.e. rejection of the null hypothesis). ANOVA results for all the other variables gave p-values higher than 0.05 , which meant that the differences in the amount of transferred explosive residues between subjects from their second to tenth fingerprint were not statistically significant.

A popular way to investigate the cause of rejection of the null hypothesis is the multiple comparison procedure. Therefore, this procedure was applied to the ANOVA of the first variable (the first fingerprint) to determine which means were significantly different from which others. The Fisher's LSD estimated difference between each pair of means showed that out of 45 pairs (all possible combinations among the ten persons), 14 pairs of means showed statistically significant differences at a 95.0\% confidence level. From Table 3 it can be seen that five groups were created using columns of X's. Within each column, the levels containing X's form a group of means within which there were no statistically significant differences.

Table 3. Multiple comparison procedure of the ANOVA results of the first fingerprint for the ten subjects.

\begin{tabular}{|l|c|c|c|c|c|}
\hline & \multicolumn{4}{|c|}{$\begin{array}{c}\text { Groups in which } \\
\text { transfer is not } \\
\text { significantly } \\
\text { different }\end{array}$} \\
\hline Subject 1 & $\mathrm{X}$ & & & & \\
\hline Subject 2 & $\mathrm{X}$ & $\mathrm{X}$ & & & \\
\hline Subject 3 & $\mathrm{X}$ & $\mathrm{X}$ & $\mathrm{X}$ & & \\
\hline Subject 4 & $\mathrm{X}$ & $\mathrm{X}$ & $\mathrm{X}$ & $\mathrm{X}$ & \\
\hline Subject 5 & & $\mathrm{X}$ & $\mathrm{X}$ & $\mathrm{X}$ & $\mathrm{X}$ \\
\hline Subject 6 & & & $\mathrm{X}$ & $\mathrm{X}$ & $\mathrm{X}$ \\
\hline Subject 7 & & & $\mathrm{X}$ & $\mathrm{X}$ & $\mathrm{X}$ \\
\hline Subject 8 & & & $\mathrm{X}$ & $\mathrm{X}$ & $\mathrm{X}$ \\
\hline Subject 9 & & & & $\mathrm{X}$ & $\mathrm{X}$ \\
\hline Subject 10 & & & & & $\mathrm{X}$ \\
\hline
\end{tabular}

Surprisingly, even though there were significant differences in the explosive amount present in the first fingerprint between some specific subjects, Table 3 reveals that none of the subjects differed markedly from the others. The amount of transferred explosive residues in consecutive fingerprints remained in a definite similar range for all subjects. For example, even though there were statistically significant differences (considering the 
first fingerprint) between subjects 1 and 10, no statistical differences between subjects 1 and 4 , neither between subjects 4 and 9 or between subjects 9 and 10 were observed.

Despite the statistically significant differences that may occur between some persons in the explosive amount in their first fingerprint, there are no differences that perfectly distinguish people's transfer behaviour. In conclusion, there is not a significant influence from the person when transferring the explosives while following a standardized procedure.

\subsection{Transfer of residues of nine explosives in ten consecutive fingerprints to} cotton fabric or polycarbonate plastic

The transfer of residues of nine different explosives (HMTD, TNT, PETN, black powder, dynamite, $\mathrm{ANFO}, \mathrm{NH}_{4} \mathrm{NO}_{3}, \mathrm{KNO}_{3}$ and $\mathrm{NaClO}_{3}$ ) in ten fingerprints to two surfaces, cotton fabric and polycarbonate plastic, was investigated. It was evidenced in the preceding experiment that the transfer of explosive residues was not strongly influenced by the person doing it when following a standardized procedure. Therefore, only one person (doing three replicates per explosive residue and surface) participated in all the experiments.

As in the preceding experiment, the weighing pan with the explosive residues was balanced before and after pressing the finger on it to determine the amount of explosive which had adhered to the subjects' fingertips. Interestingly, residues of $\mathrm{NH}_{4} \mathrm{NO}_{3}, \mathrm{KNO}_{3}$, $\mathrm{NaClO}_{3}, \mathrm{ANFO}$, dynamite, TNT and HMTD adhered to fingertips almost entirely from the weighing pan - the adherence of residues to the fingertip after one touch was $93 \pm 4 \%$ $(n=42)$. However, the amount of black powder and PETN adhered to the person's fingertip after the first pressing was lower and more variable compared to the other explosives, being $62 \pm 11 \%(n=6)$ and $72 \pm 8 \%(n=6)$, respectively.

Fig. 3 displays, as an example, one replicate of ten successive fingerprints containing HMTD, TNT, black powder and $\mathrm{KNO}_{3}$ on cotton fabric and polycarbonate plastic. As can be visually observed from the figure, the amount of residues of explosives transferred through fingerprints significantly varies for every explosive. In addition, there seems to be differences in the transferred explosive amount between consecutive impressions. In 
fact, there are several studies that demonstrated some variability in the amount of transferred explosive from one fingerprint to the next $[10,34,35]$. However, no farreaching conclusions can be drawn on the basis of visual examination only. Therefore, in this study information contained in the multispectral image was maximized by quantifying the pixels containing explosive residues.

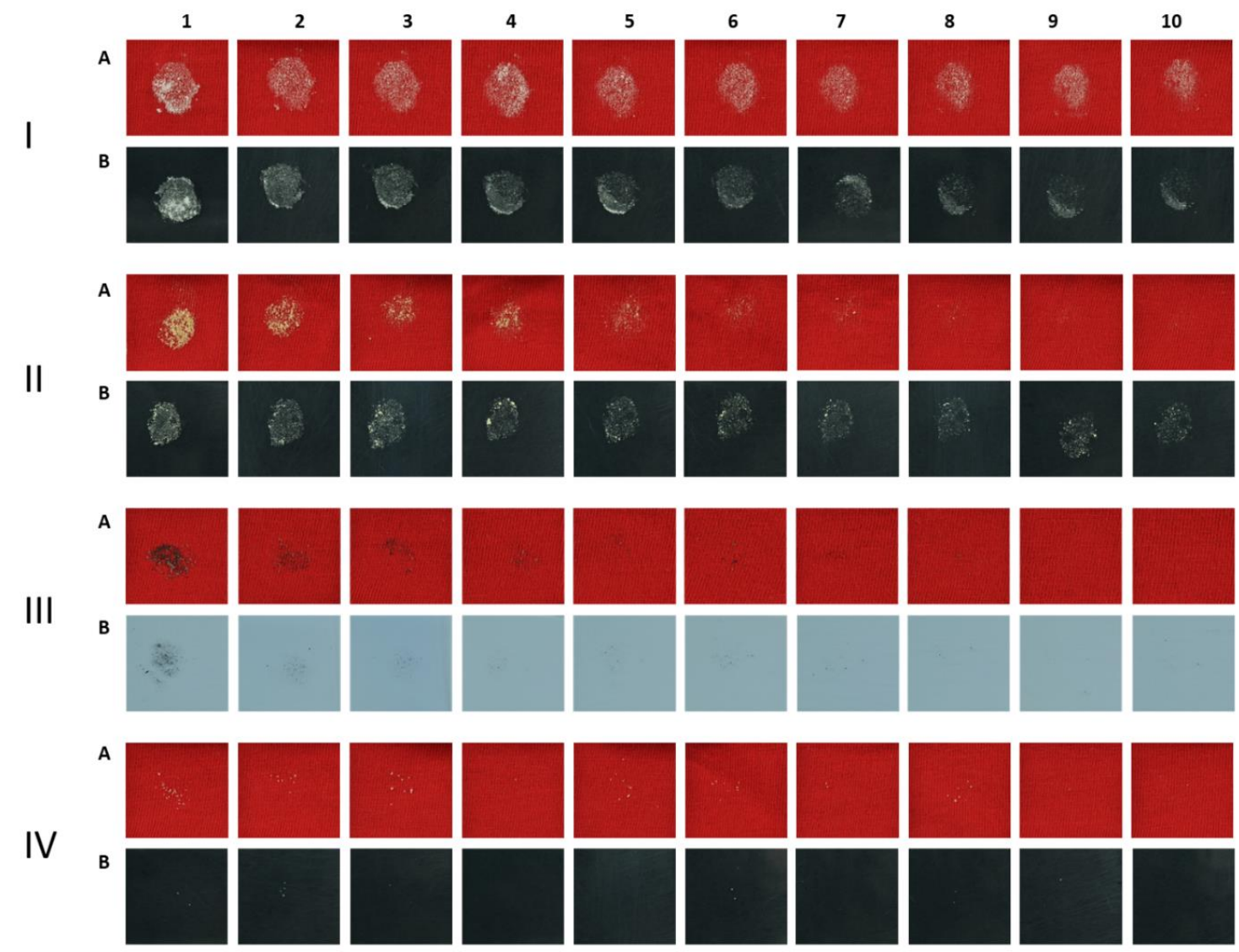

Fig. 3. Transfer of explosive residues in ten successive fingerprints to cotton fabric (A) and polycarbonate plastic (B). I - HMTD, II - TNT, III - black powder, IV - $\mathrm{KNO}_{3}$.

According to the obtained results, two entirely different tendencies could be observed in the transfer of explosive residues through consecutive fingerprints when using a standardized procedure. On the one hand, organic explosives (HMTD, TNT, PETN), black powder and dynamite evidenced a particular decrease in the amount of transferred residues through consecutive fingerprints. On the other hand, no clear decrease in the amount of transferred residues of oxidizing inorganic salts $\left(\mathrm{NH}_{4} \mathrm{NO}_{3}, \mathrm{KNO}_{3}, \mathrm{NaClO}_{3}\right)$ and ANFO (composed of $90 \% \mathrm{NH}_{4} \mathrm{NO}_{3}$ ) through consecutive fingerprints was noticed. Instead, a random transfer of residues of these explosives was noticed.

The transferred amount of residues of HMTD, TNT, PETN, black powder and dynamite showed a clear decrease (either power or exponential) as illustrated in Fig. 4. Fig. 4 
displays the quantification of pixels containing explosive residues (y-axis) on consecutive fingerprints (x-axis) together with the respective fitted functions for the transfer of each explosive, as well as their mathematical equations and coefficients of determination.

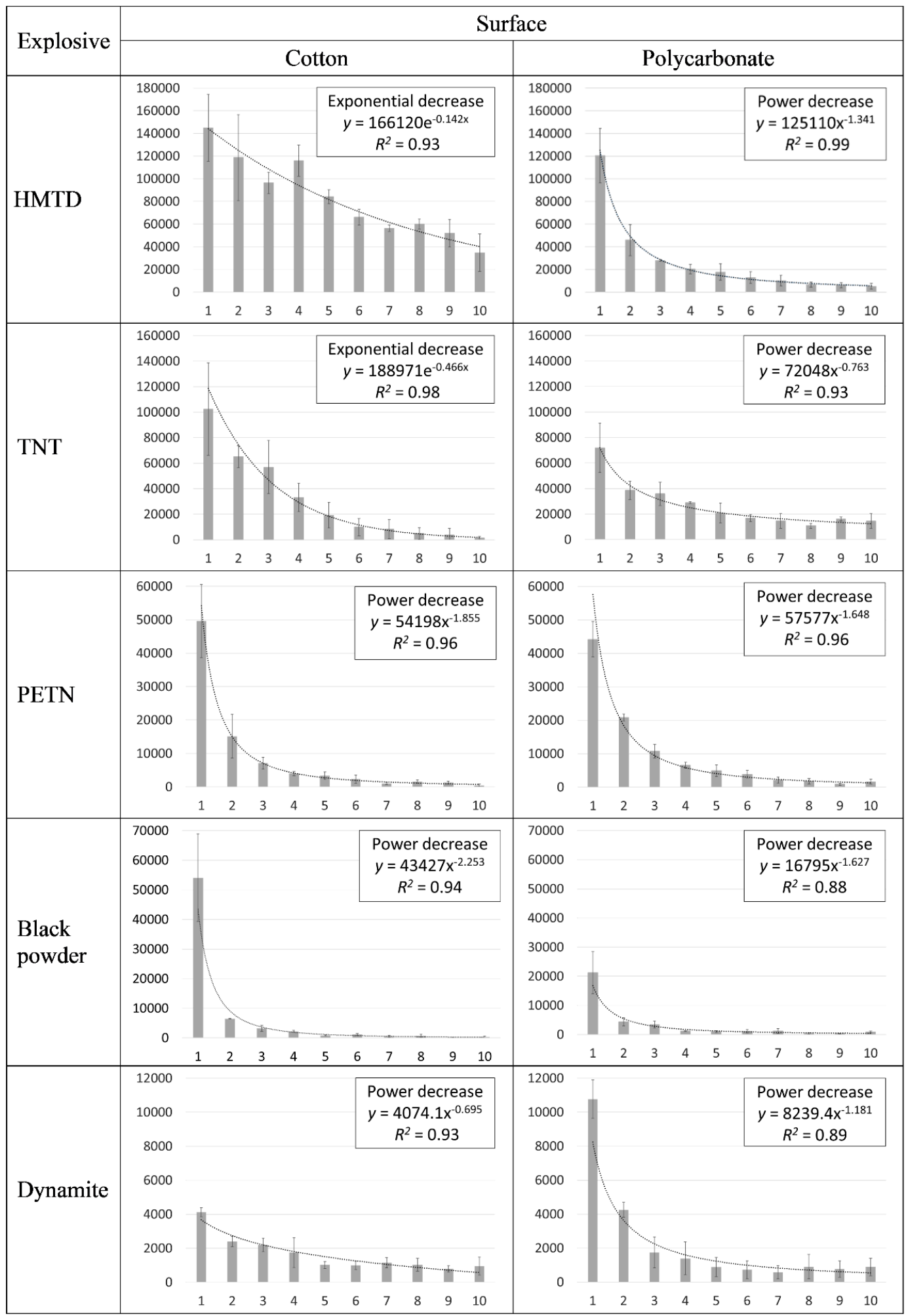

Fig. 4. Bar graphs, fitting trendlines, mathematical equations and coefficients of determination showing the amounts of transferred explosive residues undergoing a particular decrease along the ten consecutive fingerprints. $\mathrm{X}$-axis: ten consecutive fingerprints, $\mathrm{y}$-axis: amount of pixels containing explosive residues. 
The amount of HTMD transferred to both surfaces under study was clearly the highest. Large number of residues of this explosive could be found in all fingerprints, including the tenth. It should be pointed out that HMTD represented the finest powder (average particle diameter $20 \mu \mathrm{m}$ ), which could explain the higher amounts of transferred residues of this explosive compared to the other explosives. However, the amounts of HMTD residues transferred to cotton fabric and polycarbonate plastic somewhat differed. Specifically, the amount of HMTD transferred to polycarbonate plastic fitted perfectly a power function $\left(\mathrm{R}^{2}=0.99\right)$, while the amount transferred to cotton fabric presented a slighter decrease (exponential) through consecutive fingerprints and underwent some dispersion that accounted for the lower value of $\mathrm{R} 2$.

The amount of TNT transferred to both surfaces was also higher compared to the other explosives. Based on the quantification of the pixels containing explosive residues (Fig. 4), the transfer of TNT in fingerprints also depended on the target surface. There was a clear decrease through ten fingerprints to cotton fabric - there were only a few particles left by the last fingerprints. This decrease could be explained by an exponential function with $\mathrm{R}^{2}$ of 0.98 . On the other hand, the transfer of TNT to polycarbonate plastic followed a tendency that fitted the power function $\left(\mathrm{R}^{2}=0.93\right)$.

The patterns of transfer of PETN to both materials were very similar and the amounts transferred showed a clear decrease in consecutive fingerprints. The transfer of PETN to cotton fabric and polycarbonate plastic was best described by power functions with R2 being 0.96 for both surfaces.

The transfer of black powder was characterized by a huge amount of residues left in the first fingerprint on both surfaces (see Fig. 4), while the second fingerprint contained approximately five to eight times less residues than the first. One explanation to this may be related to the dryness of black powder (due to the charcoal present) and therefore it did not adhere very firmly to the finger, so after the first touch almost the whole amount of explosive fell off from the finger to the surface. Since there were a lot of particles in the first fingerprint and few particles by the last fingerprints, this decay was explained best by power functions, $\mathrm{R}^{2}$ being 0.94 and 0.88 for cotton fabric and polycarbonate plastic, respectively.

Similarly to PETN and black powder, the transfer of dynamite fitted best power functions to both surfaces $\left(\mathrm{R}^{2}\right.$ was 0.93 and 0.89 for cotton fabric and polycarbonate plastic, 
respectively). However, the amounts of residues transferred to polycarbonate plastic (especially in the first fingerprints) were higher than those transferred to cotton fabric.

In general, it was noticed that the transfer of explosive residues was not only affected by the type of explosive, but also by the surface to which the residues were transferred. In fact, the amount of transferred organic explosives HMTD and TNT underwent an exponential decrease when transferred to cotton fabric, while a power decrease when transferred to polycarbonate plastic. The transfer of PETN, black powder and dynamite fitted best the power decrease in case of both surfaces, indicating that these explosives influenced their transfer more than the surface to which they were transferred.

The transfer of residues of $\mathrm{NH}_{4} \mathrm{NO}_{3}, \mathrm{KNO}_{3}, \mathrm{NaClO}_{3}$ and $\mathrm{ANFO}$ was quite chaotic with ten consecutive fingerprints to cotton fabric and polycarbonate plastic (see Fig. 5).

The pattern of transfer of inorganic salts $\mathrm{NH}_{4} \mathrm{NO}_{3}, \mathrm{KNO}_{3}$ and $\mathrm{NaClO}_{3}$ to both surfaces under study was rather random and unpredictable. However, as displayed in Fig. 5, the amount of residues transferred to polycarbonate plastic was very low, on several occasions the number of pixels containing residues was almost zero, as against cotton fabric. Among these three inorganic salts, $\mathrm{NaClO}_{3}$ showed the lowest degree of transfer, while the amount of $\mathrm{KNO}_{3}$ transferred was the highest. Overall, the transfer of inorganic salts by fingertip was poor (up to 24,000 explosive-pixels for salt explosive residues, while up to 167,000 pixels for organic explosive residues). Due to their high hygroscopicity the salt particles tended to adhere to the bare finger rather than to be transferred to another surface. What is more, the hygroscopic salts formed aggregates which occasionally dropped from the finger during the transfer procedure. This behaviour explained the huge standard deviations obtained for these salts since already one large particle of $\mathrm{KNO}_{3}$ or $\mathrm{NH}_{4} \mathrm{NO}_{3}$ could contain 1000 pixels. Therefore, the occasional transfer of a couple of explosive particles increased significantly the standard deviation value. Turano [34] also suggested that variations in his work were likely due to the salt aggregates formed.

The amount of ANFO transferred to cotton fabric showed a doubtful decrease not fitting well to either the power or exponential function. In fact, the pattern of transfer of ANFO to cotton fabric was similar to that of inorganic salts, which is well understood since ANFO consists of $90 \% \mathrm{NH}_{4} \mathrm{NO}_{3}$. However, to both surfaces the amount of ANFO particles transferred was higher compared to those of $\mathrm{NH}_{4} \mathrm{NO}_{3}$. The particles of ANFO were oily (one component of which is fuel oil) and when pressuring on them with a warm 
fingertip, the particles became aggregated. This resulted in the adherence of the particles to the bare finger, making the transfer less controllable. For instance, one big aggregate may correspond to 3600 pixels in the image, while a smaller particle contained about 30 pixels. This explains the large error (standard deviation) in the transferred amounts when an aggregate is inevitably formed and dropped during the transfer procedure. The amount of ANFO particles transferred to polycarbonate plastic in each fingerprint was similar and no decrease in the transferred amount in consecutive fingerprints was observed.

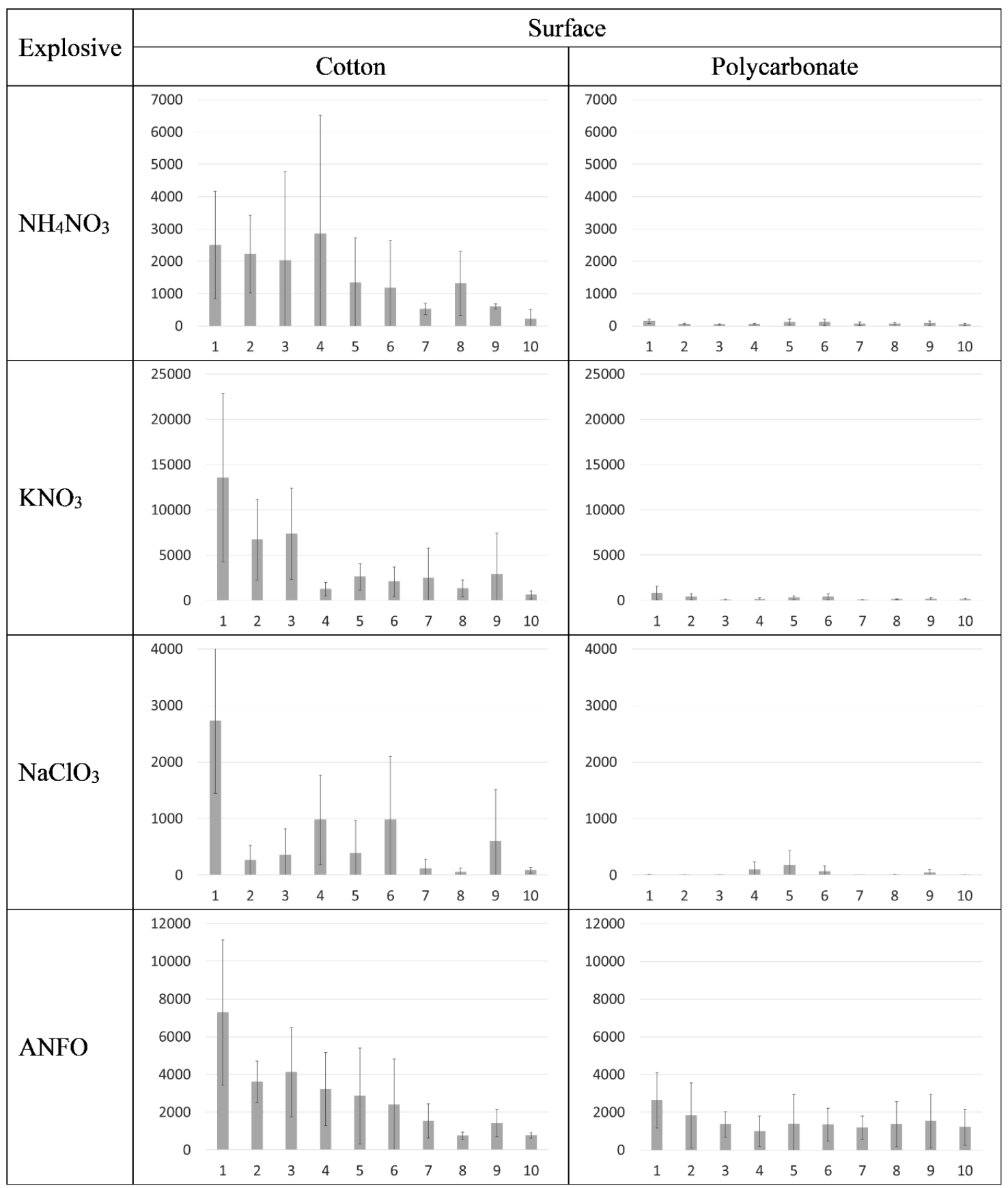

Fig. 5. Bar graphs and standard deviations showing the transfer of explosive residues of random nature through ten consecutive fingerprints. $X$-axis: ten consecutive fingerprints; $y$-axis: amount of pixels containing explosive residues. 


\section{Conclusions}

A pioneering fundamental study evaluating the transfer of explosive residues through ten consecutive fingerprints to two different surfaces - cotton fabric and polycarbonate plastic - was carried out using a simple RGB-multispectral imaging approach. The contrast in images was maximized utilizing advantageous coloured backgrounds and selecting the proper frame. This enabled us to estimate the amount of transferred explosive residues through the number of pixels in the image containing explosive residues. Despite the small inequality that may exist between the amount of explosive residues and number of pixels, on the basis of the results obtained, some general conclusions can be drawn.

First, it was shown using PETN as an example that a person does not seem to have a significant impact on the transfer of explosive residues when following a standardized procedure - similar transfer patterns of PETN residues were observed for all subjects. Nevertheless, for stating a general conclusion, further studies with involvement of more subjects and explosives would give more reliable results.

Regarding explosives, large amount of residues of organic explosives HMTD and TNT were transferred showing either an exponential or power decrease. The amount of residues of PETN, black powder and dynamite transferred throughout ten fingerprints was lower, but nonetheless displayed a power decrease on both surfaces, cotton fabric and polycarbonate plastic. On the other hand, no decrease of the transferred amounts of inorganic oxidizing salts $\left(\mathrm{NH}_{4} \mathrm{NO}_{3}, \mathrm{KNO}_{3}\right.$ and $\left.\mathrm{NaClO}_{3}\right)$ and $\mathrm{ANFO}$ was observed - the transfer seemed to be mainly governed by random effects.

Regarding the surfaces under study, cotton fabric and polycarbonate plastic, in general, higher amounts of explosive residues were left on the former, which was probably due to the stronger adherence of explosive residues to its fibres than to the smooth surface of polycarbonate plastic. In addition, a sharper decrease in the amount of explosive residues transferred with ten fingerprints to polycarbonate plastic was observed (the transferred amounts of all the explosive residues that presented a decrease, exhibited a power decrease in polycarbonate plastic). 
In general, the results obtained may contribute to the scarcely investigated, yet important field - the transfer of explosives through fingerprints to different materials. To date, most investigations have dealt with the trace detection of explosive residues but only few of them have focused on studying the explosives transfer. In fact, still a huge amount of work remains to be done in order to have a more accurate understanding about the transfer pattern of explosives. Further studies including other explosives and ammunitions should be carried out, involving more subjects and more replicates, as well as higher number of fingerprints, to have more representative results. These proposed studies would further increase the knowledge about the transfer pattern of different explosives in various circumstances.

\section{Acknowledgements}

The authors greatly thank Fernando Ortega and Víctor Toledo for their help in setting the home-built photo studio. The authors acknowledge Mercedes Torre for her assistance with Statgraphics software and in performing ANOVA. Heidi Lees acknowledges the European Regional Development Fund, Estonian Government, the Estonian Ministry of Defense and The Estonian Research Council (IUT 33-20) for the financial support. Félix Zapata is grateful to the Spanish Ministry of Education for his Ph.D. research fellowship (FPU014/00790).

\section{Conflicts of interest}

The authors have declared no conflicts of interest.

\section{References}

[1] M.Á. Fernández de la Ossa, J.M. Amigo, C. García-Ruiz, Detection of residues from explosive manipulation by near infrared hyperspectral imaging: a promising forensic tool, Forensic Sci. Int. 242 (2014) 228-235, http://dx.doi.org/10.1016/j.forsciint.2014.06.023. 
[2] M.Á. Fernández de la Ossa, C. García-Ruiz, J.M. Amigo, Near infrared spectral imaging for the analysis of dynamite residues on human handprints, Talanta 130 (2014) 315-321, http://dx.doi.org/10.1016/j.talanta.2014.07.026.

[3] F. Zapata, M.Á. Fernández de la Ossa, E. Gilchrist, L. Barron, C. García-Ruiz, Progressing the analysis of improvised explosive devices: comparative study for trace detection of explosive residues in handprints by Raman spectroscopy and $\begin{array}{lllll}\text { liquid } & \text { chromatography, } & \text { Talanta } & \text { (2016) }\end{array}$ http://dx.doi.org/10.1016/j.talanta.2016.05.057.

[4] D. Perret, S. Marchese, A. Gentili, R. Curini, A. Terracciano, E. Bafile, F. Romolo, LC-MS-MS determination of stabilizers and explosives residues in hand-swabs, Chromatographia $68 \quad$ (2008) 517-524, http://dx.doi.org/10.1365/s10337-008-0746-8.

[5] F.S. Romolo, L. Cassioli, S. Grossi, G. Cinelli, M.V. Russo, Surface-sampling and analysis of TATP by swabbing and gas chromatography/mass spectrometry, Forensic Sci. Int. $224 \quad$ (2013) 96-100, http://dx.doi.org/10.1016/j.forsciint.2012.11.005.

[6] N. Song-im, S. Benson, C. Lennard, Establishing a universal swabbing and cleanup protocol for the combined recovery of organic and inorganic explosive residues, Forensic Sci. Int. $223 \quad$ (2012) 136-147, http://dx.doi.org/10.1016/j.forsciint.2012.08.017.

[7] K. Szomborg, F. Jongekrijg, E. Gilchrist, T. Webb, D. Wood, L. Barron, Residues from low-order energetic materials: the comparative performance of a range of sampling approaches prior to analysis by ion chromatography, Forensic Sci. Int. 233 (2013) 55-62, http://dx.doi.org/10.1016/j.forsciint.2013.08.018.

[8] D.A. Detata, P.A. Collins, A.J. McKinley, A comparison of common swabbing materials for the recovery of organic and inorganic explosive residues, J. Forensic Sci. 58 (2013) 757-763, http://dx.doi.org/10.1111/1556-4029.12078.

[9] J.R. Verkouteren, Particle characteristics of trace high explosives: RDX and PETN, J. Forensic Sci. 52 (2007) 335-340, http://dx.doi.org/10.1111/j.15564029.2006.00354.x.

[10] J.R. Verkouteren, J.L. Coleman, I. Cho, Automated mapping of explosives particles in composition C-4 fingerprints, J. Forensic Sci. 55 (2010) 334-340, http://dx.doi.org/10.1111/j.1556-4029.2009.01272.x. 
[11] D.J. Phares, J.K. Holt, G.T. Smedley, R.C. Flagan, Method for characterization of adhesion properties of trace explosives in fingerprints and fingerprint simulations, J. Forensic Sci. 45 (2000) 774-784, http://dx.doi.org/10.1520/JFS14770J.

[12] P. Lucena, I. Gaona, J. Moros, J.J. Laserna, Location and detection of explosive contaminated human fingerprints on distant targets using standoff laserinduced breakdown spectroscopy, Spectrochim. Acta - Part B At. Spectrosc. 85 (2013) 71-77, http://dx.doi.org/10.1016/j.sab.2013.04.003.

[13] E.D. Emmons, A. Tripathi, J.A. Guicheteau, S.D. Christesen, A.W. Fountain III, Raman chemical imaging of explosive-contaminated fingerprints, Appl. Spectrosc. 63 (2009) 1197-1203, http://dx.doi.org/10.1366/000370209789806812.

[14] A. Tripathi, E.D. Emmons, P.G. Wilcox, J.A. Guicheteau, D.K. Emge, S.D. Christesen, A.W. Fountain, Semi-automated detection of trace explosives in fingerprints on strongly interfering surfaces with Raman chemical imaging, Appl. Spectrosc. 65 (2011) 611-619, http://dx.doi.org/10.1366/10-06214.

[15] Y. Mou, J.W. Rabalais, Detection and identification of explosive particles in fingerprints using attenuated total Reflection-Fourier transform infrared spectromicroscopy, J. Forensic Sci. 54 (2009) 846-850, http://dx.doi.org/10.1111/j.1556-4029.2009.01060.x.

[16] S. Almaviva, S. Botti, L. Cantarini, A. Palucci, A. Puiu, F. Schnuerer, W. Schweikert, F.S. Romolo, Raman spectroscopy for the detection of explosives and their precursors on clothing in fingerprint concentration: a reliable technique for security and counterterrorism issues, Proc. SPIE 8901 (2013) 890102/1890102/9, http://dx.doi.org/10.1117/12.2028855.

[17] P.H.R. Ng, S. Walker, M. Tahtouh, B. Reedy, Detection of illicit substances in fingerprints by infrared spectral imaging, Anal. Bioanal. Chem. 394 (2009) 2039-2048, http://dx.doi.org/10.1007/s00216-009-2806-9.

[18] J.S. Caygill, F. Davis, S.P.J. Higson, Current trends in explosive detection $\begin{array}{lllll}\text { techniques, } & \text { Talanta } & 88 & \text { (2012) }\end{array}$ http://dx.doi.org/10.1016/j.talanta.2011.11.043.

[19] T. Peng, W. Qin, K. Wang, J. Shi, C. Fan, D. Li, Nanoplasmonic imaging of latent fingerprints with explosive RDX residues, Anal. Chem. 87 (2015) 94039407, http://dx.doi.org/10.1021/acs.analchem.5b02248. 
[20] Y. Ma, H. Li, S. Peng, L. Wang, Highly selective and sensitive fluorescent paper sensor for nitroaromatic explosive detection, Anal. Chem. 84 (2012) 84158421, http://dx.doi.org/10.1021/ac302138c.

[21] T.P. Forbes, E. Sisco, Mass spectrometry detection and imaging of inorganic and organic explosive device signatures using desorption electro-flow focusing ionization, Anal. Chem. $86 \quad$ (2014) 7788-7797, http://dx.doi.org/10.1021/ac501718j.

[22] M. Abdelhamid, F.J. Fortes, M.A. Harith, J.J. Laserna, Analysis of explosive residues in human fingerprints using optical catapulting-laser-induced breakdown spectroscopy, J. Anal. At. Spectrom. 26 (2011) 1445-1450, http://dx.doi.org/10.1039/c0ja00188k.

[23] J. Moros, J. Serrano, F.J. Gallego, J. Macias, J.J. Laserna, Recognition of explosives fingerprints on objects for courier services using machine learning methods and laser-induced breakdown spectroscopy, Talanta 110 (2013) 108117, http://dx.doi.org/10.1016/j.talanta.2013.02.026.

[24] C.G. Worley, S.S. Wiltshire, T.C. Miller, G.J. Havrilla, V. Majidi, Detection of visible and latent fingerprints using micro-X-ray fluorescence elemental imaging, J. Forensic Sci. 51 (2006) 57-63, http://dx.doi.org/10.1111/j.1556-4029.2005.00006.x.

[25] A. Banas, K. Banas, M.B.H. Breese, J. Loke, B. Heng Teo, S.K. Lim, Detection of microscopic particles present as contaminants in latent fingerprints by means of synchrotron radiation-based Fourier transform infra-red microimaging, Analyst 137 (2012) 3459-3465, http://dx.doi.org/10.1039/c2an35355e.

[26] N.J. Crane, E.G. Bartick, R.S. Perlman, S. Huffman, Infrared spectroscopic imaging for noninvasive detection of latent fingerprints, J. Forensic Sci. 52 (2007) 48-53, http://dx.doi.org/10.1111/j.1556-4029.2006.00330.x.

[27] T. Chen, Z.D. Schultz, I.W. Levin, Infrared spectroscopic imaging of latent fingerprints and associated forensic evidence, Analyst 134 (2009) 19021904, http://dx.doi.org/10.1039/b908228j.

[28] E.D. Emmons, A. Tripathi, J.A. Guicheteau, S.D. Christesen, A.W. Fountain III, Raman chemical imaging of explosive-contaminated fingerprints, Appl. Spectrosc. $63 \quad$ (2009) 1197-1203, http://dx.doi.org/10.1366/000370209789806812. 
A. Tripathi, E.D. Emmons, J.A. Guicheteau, S.D. Christesen, P.G. Wilcox, D.K. Emge, A.W. Fountain III, Trace explosive detection in fingerprints with Raman chemical imaging, Proc. SPIE 7665 (2010), http://dx.doi.org/10.1117/12.865769 76650N/1-76650N/6.

[30] H. Östmark, M. Nordberg, T.E. Carlsson, Stand-off detection of explosives particles by multispectral imaging Raman spectroscopy, Appl. Opt. 50 (2011) 5592-5599, http://dx.doi.org/10.1364/AO.50.005592.

[31] I. Malka, A. Petrushansky, S. Rosenwaks, I. Bar, Detection of explosives and latent fingerprint residues utilizing laser pointer-based Raman spectroscopy, Appl. Phys. B Lasers Opt. 113 (2013) 511-518, http://dx.doi.org/10.1007/s00340-013-5500-8.

[32] M.R. Almeida, L.P.L. Logrado, J.J. Zacca, D.N. Correa, R.J. Poppi, Raman hyperspectral imaging in conjunction with independent component analysis as a forensic tool for explosive analysis: the case of an ATM explosion, Talanta 174 (2017) 628-632, http://dx.doi.org/10.1016/j.talanta.2017.06.064.

[33] B.E. Bernacki, T.A. Blake, A. Mendoza, T.J. Johnson, Visible hyperspectral imaging for standoff detection of explosives on surfaces, Proc. SPIE 7838 (2010), http://dx.doi.org/10.1117/12.870739 78380C/1-78380C/7.

[34] M.A. Turano, Transfer of Residues in Fingerprints, University of Rhode Island, Kingston, Rhode Island, U.S.A., 2013 〈http://digitalcommons.uri.edu/theses/153〉.

[35] G.L. Gresham, J.P. Davies, L.D. Goodrich, L.G. Blackwood, B.Y.H. Liu, D. Thimsem, S.H. Yoo, S.F. Hallowell, Development of particle standards for testing detection systems: mass of RDX and particle size distribution of composition 4 residues, Proc. SPIE $2276 \quad$ (1994) 34-44, http://dx.doi.org/10.1117/12.189198.

[36] S.-S. Choi, C.E. Son, Analytical method for the estimation of transfer and detection efficiencies of solid state explosives using ion mobility spectrometry and smear matrix, Anal. Methods 9 (2017) 2505-2510, http://dx.doi.org/10.1039/ C7AY00529F.

[37] F. Zapata, M. López-López, J.M. Amigo, C. García-Ruiz, Multi-spectral imaging for the estimation of shooting distances, Forensic Sci. Int. 282 (2018) 8085, http://dx.doi.org/10.1016/j.forsciint.2017.11.025. 